\title{
Intraventricular Transplantation of Autologous Bone Marrow Mesenchymal Stem Cells for Stroke: Rationale, Technique and Early Clinical Experience
}

\author{
Asra Al Fauzi \\ Department of Neurosurgery - Medical Faculty Universitas Airlangga, Surabaya
}

\begin{abstract}
Keywords: Bone Marrow Mesenchymal Stem Cells, Hemorrhagic Stroke, Intraventricular Transplantation, Technique, Outcome

Abstract: $\quad$ Stroke, one of the most devastating diseases, is a leading cause of death and disability throughout the world and is also associated with emotional and economic problems. The main purpose of this article is to report the technique and clinical outcome of the intraventricular transplantation of bone marrow mesenchymal stem cells (BM-MSCs) in post-hemorrhagic stroke patients. This clinical study was performed with eight patients with supratentorial hemorrhagic stroke, who had undergone 24 weeks of standard treatment of stroke with stable neurological deficits. All of the patients received stem cell transplantation intraventricularly via an Ommaya reservoir using autologous BM-MSCs. Six months and twelve months after stem cell treatment, the clinical outcomes were measured using the National Institute of Health Stroke Scale (NIHSS).The results of this study showed improvement of NIHSS score values before and after the treatment in 5 patients. No adverse effects or complications were detected during the 1 year of observation. Intraventricular transplantation of BM-MSCs showed benefits in improving the functional status of post-hemorrhagic stroke patients. The repeated transplantation procedure is easier and safer to perform via a subcutaneously implanted Ommaya reservoir.
\end{abstract}

\section{INTRODUCTION}

Stroke remains a leading cause of morbidity and mortality, with a prevalence rate of about 250$300 / 100,000$ of the total population in Asian countries (Bhasin et al., 2011). Approximately $30 \%$ of stroke patients become severely disabled and are left with permanent functional disabilities (Kondziolka et al., 2005). Early intervention and active rehabilitation still represent the standard therapy for minimizing brain damage and maximizing functional recovery after stroke. However, once functional recovery reaches the plateau phase and any neurological deficits become fixed, patients face severe difficulties, because there is still no known proven treatment (Kondziolka et al., 2005). Spontaneous intracerebral hemorrhage (ICH) causes $10-20 \%$ of all strokes (Seyfried et al., 2006), with outcomes much worse than those of ischemic stroke (Keep et al., 2012; Seyfried et al., 2010). By its nature, ICH causes a variety of neural injury mechanisms: mechanical injury, toxicity, ischemia, inflammation and apoptosis (Seyfried et al., 2006). Despite ongoing attempts to find better treatments based on the pathomechanism of this disease, the outcomes remain poor (Rincon \& Mayer, 2008). Nowadays, much attention has been focused on neurorestorative therapies, including stem cell transplantation. Several investigations have reported that direct transplantation or systemic infusion of stem cells results in neurofunctional improvement not only because of the cell replacement mechanism (to replace) but also because the local host environment is stimulated with various trophic and growth factors secreted by transplanted cells (to stimulate) (Guzman et al., 2008; Hammer et al., 2008). The route and site of stem cell delivery remain significant issues. Several studies have reported neurofunctional recovery with the intravenous, intracerebral and intraventricular routes of stem cell delivery (Kondziolka et al., 2005; Guzman et al., 2008; Jozwiak et al., 2010; Sharma et al., 2012; Bliss et al., 2007; Calió et al., 2014). For example, one study confirmed that all cells reach the target lesions, but more cells are found after intracerebral delivery followed by intraventricular and intravenous delivery 
(Guzman et al., 2008; Calió et al., 2014). The indirect route with intravenous injection is non-invasive, but it can create a homing site for other organs far from the target site in the brain (Calió et al., 2014; Chopp et al., 2008).

Bone marrow mesenchymal stem cells (BMMSCs) have recently been studied and reported as a potential stem cell source for various central nervous system diseases (Seyfried et al., 2010; Bordey, 2006; Kazanis, 2012). Compared with other sources, such as embryonic and other adult stem cells, BM-MSCs are readily accessible, easily expanded in culture and amenable to manipulation (Seyfried et al., 2010). The utilization of autologous stem cells avoids the legal and ethical issues concerning the source of transplant cells in stem cell therapy. BM-MSCs are pluripotent cells that are capable of self-renewal and differentiation in a variety of non-hematological tissues, including brain tissue (Seyfried et al., 2010).

\section{METHODS}

This study received legal/ethical clearance from the local medical research ethics committees of Dr. Soetomo General Hospital, Surabaya, Indonesia, following the regulatory guidelines of the country. Moreover, a research permit was obtained from the Research and Development Department of East Java, Indonesia Provincial Government. Prior to the study, informed consent documents, details of the medical treatment and other necessary approval documents were delivered to all patients involved in the study.

This study was designed using a one-group pretest/post-test design. The subjects of this study were postoperative supratentorial ICH patients with persistent neurological deficits after six months in Dr. Soetomo General Hospital, Surabaya, Indonesia.

The subjects of this study were supratentorial ICH patients with persistent neurological deficits after 24weeks in Dr. Soetomo General Hospital, Surabaya, Indonesia.

Eight patients were included in the study. The clinical evaluation was carried out using the National Institute of Health Stroke Scale (NIHSS) 6 and 12 months after the first procedure of transplantation. The following inclusion and exclusion criteria were used for the patients.

\section{Inclusion Criteria:}

- Hemorrhagic stroke patients

- $\quad$ Aged 45 to 65

- Supratentorial location

- No ventricular-peritoneal shunt
- $\quad$ No active infection/disease

- $\quad$ No systemic malignancies

- $\quad 24$ weeks after stroke with stable NIHSS score in last 12 weeks

Exclusion Criteria:

- Significant neurological improvement after stroke

- Did not receive optimal standard therapy

- Severe comorbid factors: pneumonia, heart diseases, diabetes mellitus, psychiatric disorders, uncontrolled hypertension

- Epilepsy

\subsection{Procedure}

Isolation and intraventricular transplantation of bone marrow mesenchymal stem cells (BM-MSCs) was performed in the operating room of Dr. Soetomo General Hospital, Surabaya.

Autologous bone marrow stromal cell isolation was performed under general anesthesia, and aspiration of BM-MSCs on iliac bone was performed with a sterile procedure.

Isolation of mononuclear (MN) cells from bone marrow samples was done using Histopaque-density centrifugation methods. Whole MN cells were obtained and then cultured in Dulbecco's Eagle medium with $10 \%$ fetal bovine serum (FBS) (Sigma Chemical) in plastic petri humidity conditions of $37^{\circ} \mathrm{C}$ with $5 \% \mathrm{CO} 2$. Unattached cells were discarded, while attached cells were expanded. After confluent cells were achieved (referred to as passage 0), cells were cultured up to passage 3 .

Characterization of BM-MSCs was performed using immunocytochemistry techniques. Cells were characterized with markers of fluorescein isothiocyanate (FITC) anti-human CD90 antibody (BioLegend, USA), phycoerythrin (PE) anti-human CD29 antibody (BioLegend, USA), peridininchlorophyll-protein complex: cyanine 5.5 conjugate (PerCp/Cy5.5) anti-human CD34 and anti-human CD45 FITC.

\subsection{Transplantation Techniques}

Under general anesthesia, patients were conditioned in a supine position. The hair was shaved just behind the right frontal hairline, and then the area was washed with antiseptic solution. A mark was then made on the right Kocher point. A $2.5-\mathrm{cm}$ wide linear incision was made in layers through the periosteum.

The process was continued by creating a burr hole in the calvaria and a small dural incision. An 
Ommaya reservoir was inserted into the ventricle, and then a maximum of $5 \mathrm{cc}$ of cerebrospinal fluid was slowly aspirated through the Ommaya reservoir with a wing needle. Then, the stem cells were transplanted with the same wing needle $(2 \times 106$ cells in $3 \mathrm{cc}$ of normal saline) and then flushed with $2 \mathrm{cc}$ of normal saline. The surgical wound was then sutured layer by layer.

For booster transplantation, the same procedures were performed without the open procedure or general anesthesia one month after the first transplantation. Hair did not need to be shaved, disinfection with povidone-iodine was performed at the skin and BM-MSC injection was carried out with the same dose using wing needle no. 25 through the subcutaneous transplanted Ommaya reservoir [Figure 1]. Booster transplantation was done twice at onemonth intervals.

\section{RESULTS}

Table 1: Data progress of post-hemorrhagic stroke and post-treatment patients.

\begin{tabular}{|c|c|c|c|c|c|c|c|}
\hline No. & $\begin{array}{l}\text { Gender } \\
(\mathrm{M} / \mathrm{F})\end{array}$ & $\begin{array}{l}\text { Age } \\
\text { (years }\end{array}$ & $\begin{array}{l}\text { Location of } \\
\text { Hemorrhage }\end{array}$ & Baseline & $\begin{array}{c}\text { 24Weeks After } \\
\text { Stroke }\end{array}$ & $\begin{array}{c}\begin{array}{c}\text { 48-Weeks } \\
\text { Evaluation }\end{array} \\
\text { NIHSS }\end{array}$ & Improvement \\
\hline 1. & $\mathrm{~F}$ & 45 & $\begin{array}{l}\text { Left Basal } \\
\text { Ganglia }\end{array}$ & 8 & 8 & 6 & $\begin{array}{l}\text { - Severe aphasia } \rightarrow \\
\text { Mild-to-moderate } \\
\text { aphasia } \\
\text { - Severe dysarthria } \rightarrow \\
\text { Mild-to-moderate } \\
\text { dysarthria }\end{array}$ \\
\hline 2. & $\mathrm{M}$ & 63 & Right Parietal & 2 & 2 & 2 & 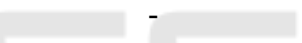 \\
\hline 3. & M & 50 & $\begin{array}{l}\text { Left Basal } \\
\text { Ganglia }\end{array}$ & 5 & 5 & 5 & - \\
\hline 4. & M & 61 & $\begin{array}{l}\text { Left Basal } \\
\text { Ganglia }\end{array}$ & 4 & $\square L 4 \square=$ & $|+3|=$ & $\begin{array}{c}\text { LOC Questions; } \\
\text { Answer one question } \\
\text { correctly } \rightarrow \text { Answer } \\
\text { both question correctly }\end{array}$ \\
\hline 5. & M & 56 & $\begin{array}{c}\text { Left } \\
\text { Frontoparieta } \\
1 \mathrm{FP}\end{array}$ & 23 & 22 & 19 & $\begin{array}{l}\text { Left \& Right Arm, } \\
\text { some effort against } \\
\text { gravity } \rightarrow \text { Drift } \\
\text { Left \& Right Leg, } \\
\text { some effort against } \\
\text { gravity } \rightarrow \text { Drift }\end{array}$ \\
\hline 6. & M & 52 & $\begin{array}{l}\text { Right Basal } \\
\text { Ganglia }\end{array}$ & 17 & 17 & 15 & $\begin{array}{l}\text { - Level of } \\
\text { consciousness; not } \\
\text { alert level } 2 \rightarrow \text { Level } \\
\text { of consciousness, } \\
\text { not alert level } 1 \\
\text { - LOC Commands; } \\
\text { Performs neither } \\
\text { task correctly } \rightarrow \\
\text { Performs one task } \\
\text { correctly }\end{array}$ \\
\hline 7. & $\mathrm{~F}$ & 59 & $\begin{array}{l}\text { Right Parieto- } \\
\text { occipital }\end{array}$ & 5 & 5 & 5 & - \\
\hline 8. & M & 48 & $\begin{array}{c}\text { Left Basal } \\
\text { Ganglia }\end{array}$ & 5 & 5 & 4 & $\begin{array}{l}\text { Limb Ataxia; present } \\
\text { in one limb } \rightarrow \text { absent }\end{array}$ \\
\hline
\end{tabular}




\subsection{Patient Characteristics}

The average age of patients in this study was $53.44 \pm$ 6.02 years. The youngest patient was 45 years old, and the oldest was 63 years old. The average age of patients was $54.25 \pm 6.50$ years.

In terms of gender, six patients $(75 \%)$ were male, and two patients $(25 \%)$ were female. All the patients had standard treatment for hemorrhagic stroke including medical treatment and physical rehabilitation. Two of the patients had surgical treatment (craniotomy and clot removal).

In terms of the site of supratentorial bleeding, five patients $(62.5 \%)$ had bleeding in the basal ganglia, one patient $(12.5 \%)$ had it in the right parietal and one patient $(12.5 \%)$ had it as a right parieto-occipital hemorrhage. Further details on patient characteristics and clinical outcome are shown in Table 1.

\subsection{Clinical Results}

From the eight patients followed for 12 months, 5 patients showed improvement in neurologic status and 3 patients showed no change. One patient showed motor repair and 2 patients showed improvement in the level of conception. Two other patients showed improvement from ataxia and improvement of aphasia and dysarthria. For a safety result evaluation, we observed the incidence of increased intracranial pressure, infection, seizures and signs of rejection from the patient's body. We did not observe any sign of such adverse effects from the 8 patients.

\subsection{Intraventricular Transplantation}

The ventricular system has thin walls composed of ependymal cells (Bordey, 2006; Kazanis, 2012). The permeable properties of ependymal cells make it quite effective for the treatment of certain medicines, including stem cell therapy targeting the brain parenchyma (Kazanis, 2012). On the lateral ventricle, the ventricular walls are surrounded by the SVZ, which continuously produces new neurons (Doetsch et al., 1999; Okano, 2002).

The SVZ was first discovered in mice, then in larger mammals, and later, it was found in humans (Bordey, 2006; Kazanis, 2012). The location of the neurogenic niche area is very close to the lateral ventricle, which explains why the administration of stem cells through the intraventricular route is an effective method for stem cell therapy in stroke. The lateral ventricles are easy to access, enabling direct stimulation of the SVZ.
Moreover, in essence, cerebrospinal fluid is the endogenous regulatory factor of neuronal differentiation in neural regeneration, where the plexus choroideus produces substances during brain development or the regeneration process after brain injury (Falcão, 2012). The occurrence of this endogenous neurogenesis has been widely reported in several studies (Okano, 2002).

Intraventricular transplantation of stem cells in hemorrhagic stroke patients has never been reported. Three previous reports related to the subject were case reports: two were children with post-hypoxic encephalopathy, while the other was a case of amyotrophic lateral sclerosis (ALS). Jozwiak et al. performed intraventricular transplantation using autologous umbilical cord stem cells on a 16-monthold child who had post-hypoxic encephalopathy with fairly good clinical results (Jozwiak et al., 2010). Baek et al. performed intraventricular transplantation using the Ommaya reservoir in cases of ALS. There were no reported complications from the study (Baek et al., 2012).

\subsection{Safety Results}

This is the first report of repeated stem cell transplantation through the intraventricular route. The application of stem cell therapy for stroke is very rational, as the principle of this therapy is to replace and repair the damaged brain tissue ( $\mathrm{Li} \&$ Ikehara, 2013). Recently, a theory suggesting that adult neural stem cells could be stimulated either exogenously or endogenously was put forth (Alonso, 2001; Okano, 2002). Some recent research studies on stem cell therapy in stroke suggest some important issues that need further research: 1) sources of optimal stem cells, 2) most effective delivery route, 3) most effective time, and 4) optimal dose (Chopp et al., 2008).

The results of the clinical evaluation of the eight patients with treatment showed no decrease in neurological status and no complications associated with the actions and effects from stem cells. Five patients showed improvement on NIHSS with different types of neurological status enhancement. Some possible side-effects that could be observed after treatment are 1) increased intracranial pressure, 2) seizures, 3) infection and 4) rejection reaction by the body. However, this study demonstrated that this technique is safe and reported no complications. One other advantage, the presence of the reservoir, facilitates repeated injections when applying booster therapy. 


\subsection{Clinical Outcomes}

NIHSS scores were used to evaluate the neurological status of the stroke patients, determine the appropriate treatment for the patients and predict the patients' prognosis (Levine et al., 2006). Determining the severity of stroke is very important in assessing the prognosis associated with the disease, including mortality, length of stay in hospital, progress of neurological deficit and functional recovery of stroke patients. A study by Williams et al. showed that the reliability of the NIHSS was almost perfect (Williams et al., 2000). Examining the NIHSS scores obtained prospectively and retrospectively is an excellent method for analyzing patients' conditions, and no bias on the scale was found in the retrospective process, although there were some missing elements of physical examinations in the medical records (Williams et al., 2000).

Kondziolka et al. implanted cultured human neural cells by the stereotactic technique in ischemic stroke patients. At the 18-month and 24-month observations, there were some functional improvements in patients (Kondziolka et al., 2000). This finding is consistent with this study. When we compared the 'before and after' conditions in stem cell transplantation, there were functional improvements in some patients.

Bang et al. reported the transplantation of BMMSCs intravenously in patients with stroke infarction evaluated at months 3,6 and 12. The results showed a significant difference in NIHSS scores in treated patients compared with controls (Bang et al., 2005). Bhasin et al. reported a significant difference among six stroke infarction patients compared with controls after the intravenous transplantation of BM-MSCs. Post-treatment clinical and radiological evaluation was performed after eight weeks (Bhasin et al., 2011). In this study, the evaluation was conducted after 48 weeks. All of the previous reports were studies on stroke infarction, whereas in this study, we conducted the research on hemorrhagic type.

Compared to ischemic stroke and subarachnoid hemorrhage, intracerebral hemorrhagic stroke has the highest mortality rate, more severe complications, and poorer long-term prognosis (Andres et al., 2008). Based on the pathology, the tissue damage is more severe compared with ischemic stroke (Andres et al., 2008). In the chronic phase, permanent damage or encephalomalacia frequently occurs, which usually does not respond to treatment, except physical rehabilitation therapy (Andres et al., 2008). Based on these conditions, stem cell transplantation tends to work through the paracrine effects of trophic factors as a neuroprotective and stimulator agent of neuronal plasticity to improve the neurological function (Andres et al., 2008). This study included cases of supratentorial hemorrhagic stroke, and after transplantation procedures were performed, there was an improvement in neurological status in some patients.

\section{CONCLUSIONS}

In this study, clinical evaluations conducted using NIHSS scores after 24 and 48 weeks of treatment showed an improvement without evidence of sideeffects or complications.Because of the small sample size and non-randomized trial performed in this study, we could not reach a definitive conclusion regarding the potential of intraventricular transplantation of BM-MSCs in chronic stroke. However, this small study shows that repeated intraventricular transplantation of autologous BMMSCs is advantageous. More advanced study is required to evaluate the efficacy of intraventricular stem cell therapy in stroke.

\section{REFERENCES}

Alonso, G., 2001. Proliferation of progenitor cells in the adult rat brain correlates with the presence of vimentinexpressing astrocytes. Glia, 34(4), pp.253-66. Available http://www.ncbi.nlm.nih.gov/pubmed/11360298.

Andres, R.H. et al., 2008. Cell replacement therapy for intracerebral hemorrhage. Neurosurgical Focus, 24(34), p.E16. Available at: http://thejns.org/doi/10.3171/FOC/2008/24/3-4/E15 [Accessed October 18, 2017].

Baek, W. et al., 2012. Stem cell transplantation into the intraventricular space via an Ommaya reservoir in a patient with amyotrophic lateral sclerosis. Journal of Neurosurgical Sciences, 56(3), pp.261-263.

Bang, O.Y. et al., 2005. Autologous mesenchymal stem cell transplantation in stroke patients. Annals of Neurology, 57(6), pp.874-882.

Bhasin, A. et al., 2011. Autologous mesenchymal stem cells in chronic stroke. Cerebrovascular diseases extra, 1(1), pp.93-104. Available at: http://www.pubmedcentral.nih.gov/articlerender.fcgi? artid $=3343764 \&$ tool $=$ pmcentrez $\&$ rendertype $=$ abstract.

Bliss, T. et al., 2007. Cell transplantation therapy for stroke. Stroke; a journal of cerebral circulation, 38(2 Suppl), pp.817-26. Available http://www.ncbi.nlm.nih.gov/pubmed/17261746.

Bordey, A., 2006. Adult Neurogenesis: Basic Concepts of Signaling. Cell Cycle, 5(7), pp.722-728. Available at: 
http://www.ncbi.nlm.nih.gov/pubmed/16582623

[Accessed October 18, 2017].

Calió, M.L. et al., 2014. Transplantation of bone marrow mesenchymal stem cells decreases oxidative stress, apoptosis, and hippocampal damage in brain of a spontaneous stroke model. Free radical biology \& medicine, 70, pp.141-54. Available at: http://www.ncbi.nlm.nih.gov/pubmed/24525001.

Chopp, M., Li, Y. \& Shen, L., 2008. Transplantation of Bone Marrow Stromal Cells for the Treatment of Stroke. In S. Savitz \& D. Rosenbaum, eds. Stroke Recovery with Cellular Therapies. Totowa, NJ: Humana Press, pp. 11-27. Available at: http://link.springer.com/10.1007/978-1-60327-05712 [Accessed October 18, 2017].

Doetsch, F. et al., 1999. Subventricular Zone Astrocytes Are Neural Stem Cells in the Adult Mammalian Brain. Cell, 97(6), pp.703-716. Available at: http://www.cell.com/article/S0092867400807837/fullt ext.

Falcão, A.M., 2012. The path from the choroid plexus to the subventricular zone: go with the flow! Frontiers in Cellular Neuroscience, 6. Available at: http://journal.frontiersin.org/article/10.3389/fncel.201 2.00034/abstract.

Guzman, R. et al., 2008. Intravascular cell replacement therapy for stroke. Neurosurgical Focus, 24(3-4), p.E15. Available http://www.ncbi.nlm.nih.gov/pubmed/18341391.

Hammer, M.D., Kondziolka, D. \& Wechsler, L.R., 2008. Safety and Efficacy of Transplanting Immortalized Neural Stem Cells in Stroke Patients. In S. Savitz \& D. Rosenbaum, eds. Stroke Recovery with Cellular Therapies. Totowa, NJ: Humana Press, pp. 1-9. Available at: http://link.springer.com/10.1007/978-160327-057-1_1 [Accessed October 18, 2017].

Jozwiak, S. et al., 2010. Intracerebroventricular Transplantation of Cord Blood-Derived Neural Progenitors in a Child With Severe Global Brain Ischemic Injury. Cell medicine, 1(2), pp.71-80. Available http://www.ncbi.nlm.nih.gov/pubmed/26966631 [Accessed October 18, 2017].

Kazanis, I., 2012. Can Adult Neural Stem Cells Create New Brains? Plasticity in the Adult Mammalian Neurogenic Niches. The Neuroscientist, 18(1), pp.15-27. Available at: http://www.ncbi.nlm.nih.gov/pubmed/21536840 [Accessed October 18, 2017].

Keep, R.F., Hua, Y. \& Xi, G., 2012. Intracerebral haemorrhage: Mechanisms of injury and therapeutic targets. The Lancet Neurology, 11(8), pp.720-731.

Kondziolka, D. et al., 2005. Neurotransplantation for patients with subcortical motor stroke: a phase 2 randomized trial. Journal of neurosurgery, 103(1), pp.38-45.

Kondziolka, D.M.D. et al., 2000. Transplantation of cultured human neuronal cells for patients with stroke. Neurology, 55(4), pp.565-569.

Levine, S. et al., 2006. Stroke Scales: An Update. National Stroke Association, 16(1), pp.1-7. Available at: https://www.yumpu.com/en/document/view/11589747 /stroke-scales-an-update-national-stroke-association.

Li, M. \& Ikehara, S., 2013. Bone-marrow-derived mesenchymal stem cells for organ repair. Stem Cells International.

Okano, H., 2002. Neural stem cells: progression of basic research and perspective for clinical application. The Keio journal of medicine, 51(3), pp.115-128.

Rincon, F. \& Mayer, S. a, 2008. Clinical review: Critical care management of spontaneous intracerebral hemorrhage. Critical care (London, England), 12(6), p.237.

Seyfried, D. et al., 2006. Effects of intravenous administration of human bone marrow stromal cells after intracerebral hemorrhage in rats. Journal of neurosurgery, 104(2), pp.313-318. Available at: http://dx.doi.org/10.3171/jns.2006.104.2.313.

Seyfried, D.M. et al., 2010. Localization of bone marrow stromal cells to the injury site after intracerebral hemorrhage in rats. Journal of Neurosurgery, 112(2), pp.329-335. Available at: http://www.ncbi.nlm.nih.gov/entrez/query.fcgi?cmd= Retrieve \&db=PubMed\&dopt $=$ Citation\&list_uids $=192$ 84233.

Sharma, A. et al., 2012. Autologous Bone Marrow Stem Cell Therapy Shows Functional Improvement in Hemorrhagic Stroke. Indian Journal of Clinical Practice, 23(2), pp.100-105.

Williams, L.S., Yilmaz, E.Y. \& Lopez-Yunez, A.M., 2000. Retrospective Assessment of Initial Stroke Severity With the NIH Stroke Scale. Stroke, 31(4), pp.858-862. Available http://stroke.ahajournals.org/content/31/4/858\%5Cnhtt p://stroke.ahajournals.org/content $/ 31 / 4 / 858$.full $\% 5 \mathrm{Cnh}$ $\mathrm{ttp} / / /$ stroke.ahajournals.org/content/31/4/858.full.pdf\% 5Cnhttp://www.ncbi.nlm.nih.gov/pubmed/10753988 